\title{
Crossing borders between frontotemporal dementia and psychiatric disorders: an updated overview
}

\author{
Matteo Vismara ${ }^{1}$, Giovanna Cirnigliaro ${ }^{1}$, Eleonora Piccoli ${ }^{1}$, Federica Giorgetti ${ }^{1}$, Laura \\ Molteni ${ }^{1}$, Laura Cremaschi ${ }^{1}$, Giorgio G. Fumagalli ${ }^{2}$, Claudio D’addario ${ }^{3}$, Bernardo \\ Dell'Osso ${ }^{1,4,5}$ *
}

1 University of Milan, Department of Mental Health, Department of Biomedical and Clinical Sciences Luigi Sacco, Milan, Italy.

${ }^{2}$ Fondazione IRCCS Ca' Granda, Ospedale Policlinico, Milan, Italy.

3

${ }^{4}$ Department of Psychiatry and Behavioral Sciences, Bipolar Disorders Clinic, Stanford University, CA, USA.

5 “Aldo Ravelli" Center for Neurotechnology and Brain Therapeutic, University of Milan, Milan, Italy.

* Corresponding Author:

Prof. Bernardo Dell'Osso,

Department of Psychiatry, Department of Biomedical and Clinical Sciences "Luigi Sacco", Psychiatry Unit 2, ASST Sacco-Fatebenefratelli, Via G.B. Grassi, 74, 20157, Milan, Italy, Phone+390239042803, email: bernardo.dellosso@unimi.it

Words count:

Manuscript: 6242

Abstract: 206

References: 85

Tables: 2 


\section{ABSTRACT}

Frontotemporal dementia (FTD) includes a group of neurocognitive syndromes, clinically characterized by altered behaviors, impairment of language proficiency, and altered executive functioning. FTD is one of the most frequently observed forms of dementia in the elderly population and the most common in presenile age. As for other subtypes of dementia, FTD incidence is constantly on the rise due to the steadily increasing age of the population, and its recognition is now becoming a determinant for clinicians. FTD and psychiatric disorders can overlap in terms of clinical presentations by sharing a common genetic predisposition and neuropathological mechanism in some cases. Nonetheless, this association is often unclear and underestimated.

Since its first reports, research into FTD has constantly grown, with the identification of recent findings related to its neuropathology, genetic, clinical, and therapeutic issues. Literature is thriving on this topic, with numerous research articles published in recent years. In the present review, we aimed to provide an updated description of the clinical manifestations that link and potentially confound the diagnosis of FTD and psychiatric disorders in order to improve their differential diagnosis and early detection. In particular, we systematically reviewed the literature, considering articles specifically focused on the behavioral variant FTD, published after 2015 on the Pubmed database.

Keywords: Psychiatric disorders, Frontotemporal lobe dementia, Frontotemporal lobar degeneration, Behavioral Symptoms, Differential Diagnosis, Genetics, Neuroimaging, Bipolar Disorder, Schizophrenia. 


\section{Introduction}

Frontotemporal dementia (FTD) identifies a group of neurodegenerative disorders characterized by a gradual and progressive alteration in behavior or language secondary to atrophy and neuronal loss in the frontal and temporal lobes of the brain $[1,2]$. Given the numerous functions attributed to these brain regions (e.g., sensorimotor integration and motor control, language performance, emotional regulation, personality, and social behavior), diverse and severely disabling clinical syndromes might result from FTD. Two major clinical subtypes of FTD can be depicted according to their clinical presentation: behavioral variant FTD (bvFTD), which presents as a progressive deterioration and change in social behavior and conduct, and primary progressive aphasia (PPA) otherwise characterized by the slow deterioration of language function and/or semantic memory [35].

The presence of psychiatric symptoms could be considered the rule rather than the exception in all types of dementia [6]. PPA might also be associated with psychiatric manifestations. Nevertheless, language alterations most often occur before the onset of psychiatric symptoms, which should alert clinicians to the presence of a neurological disease [7]. This is not the case in bvFTD which most often presents with isolated, less characterized and diverse psychopathologies, making the differential diagnosis a challenge for the clinician [8]. More specifically, bvFTD presents progressive alterations in social behaviour, executive functioning and personality that could easily be misunderstood for primary psychiatric disorders including major depression, bipolar disorder (BD), and schizophrenia [9]. Symptoms such as apathy, disinhibition, and stereotyped/compulsive behavior, changes in eating behaviors, loss of empathy, blunting of affect, hoarding and gambling, are frequently seen in both groups of disorders [10-12]. Moreover, epidemiologic investigation shows that patients with FTD may have experienced psychiatric disorders before the onset of dementia and that patients with psychotic disorders may develop dementia more often than 
expected in the non-affected population $[6,7,13,14]$. Additionally, in recent years, several genetic causes of FTD that predispose to heterogeneous and atypical presentations - including pure psychiatric symptoms - were identified [7]. On one hand, these causes underlie the possible common pathological mechanisms between FTD and psychotic disorders, and, on the other hand, make the correct differential diagnosis a complex and articulated process $[7,8]$. Furthermore, due to the increasing aging population, neurocognitive disorders are becoming more and more prevalent [15]. Therefore, the need for physicians with expertise in understanding and correctly differentiating these disorders has increased at the same rate.

\section{Methods}

In a previous report by our group, we focused on psychiatric symptoms in FTD [7]. In the last five years, however, research in this field has been constantly active with numerous studies published in recent years that had not been included in our previous investigation. Therefore, the aim of the present review was to consider recent publications in order to update readers on the topic. Due to the aim of this review and the different clinical presentations of FTD subtypes, we primarily focused on bvFTD.

For the purpose of the present study, a literature search was performed on Pubmed which considered articles written in English and published from 2015 up until November 2019. To begin with, "frontotemporal dementia" was used as a keyword. Secondly, the following keywords were used in order to refine the results: "frontotemporal dementia" and "psychiatric symptoms". Lastly, reference lists of selected articles were screened for additional research. Authors considered all of the articles that specifically reported any association, overlap, or difference (in term of epidemiology, neurobiology, clinical presentation, and therapeutic approach) between bvFTD and 
psychiatric disorders. Articles that generally described FTD without a specific focus on psychiatric symptoms were not included in the present review.

\section{Results}

\section{Epidemiology: FTD and psychiatric symptoms}

In the United States, the estimated FTD incidence has been reported at about $3-4$ per 100,000 people per year, with a prevalence rate of about 15 - 22 per 100.000 in the age between 45 and 65 years, making FTD the second most frequent cause of dementia after Alzheimer's disease (AD) and even more frequent when early-onset dementia is considered $[9,16]$. A recent Italian study reported FTD incidence to be about 3 per 100.000 people per year [17], while the prevalence in patients aged between 45 and 65 years reached 22 per 100,000 [18]. Considering a neuropathological diagnosis, FTD was found to account 5 to 10 percent of all dementia cases [11,19].

FTD typically manifests in an earlier age compared to other types of dementia. Recent studies have demonstrated that only $10 \%$ to $30 \%$ of patients show the first symptoms before age 45 and after age 65 respectively, while almost $60 \%$ of patients have their onset between age 45 and $65[16,18]$. Although some studies have shown a higher incidence of FTD in male patients, no consistent differences in gender disparity or distribution have been reported [16,20].

With respect to FTD subtypes, bvFTD is the most common clinical form of FTD, representing almost $60 \%$ of all cases, especially in samples with early-onset dementia, with a prevalence of 13 people per $100.000[8,21]$. According to a geographical perspective, the bvFTD variant is the most common FTD variant in the United States and Europe (50-70\%), while Primary Progressive Aphasia - in its semantic variant - is the most common subtype in Asia [18,19].

Recent studies assessed the prevalence of psychiatric symptoms in bvFTD patients. Psychosis is one of the most frequent and studied psychiatric manifestations seen in FTD patients. According to 
a recent review, the prevalence of psychosis in FTD patients characterized as high as $50 \%$ of cases [22]. Gossink and colleagues found that more than $95 \%$ of patients with probable and definite bvFTD presented at least one psychotic symptom, with negative symptoms such as emotional withdrawal, blunted affect and formal thought disorders being the most frequently represented. Positive symptoms like delusions and hallucinations were only found in the $22 \%$ of the sample [23]. In a previous study, psychiatric symptoms in bvFTD patients were even more frequent, with apathy (85\%), irritability (65\%), disinhibition (60\%) and agitation/aggression $(55 \%)$ being the most represented [24]. BvFTD is highly associated with socially inappropriate behaviors such us disinhibition, irritability, mood elation, impaired social judgment and other behaviors that can mimic mania [9,11]. It is not unusual to observe compulsive behaviors and hyperorality in bvFTD patients. Compulsions, in particular, might even be the initial manifestation of the disease, which can often mimic Obsessive Compulsive Disorder (OCD) [11]. Yet, although these symptoms are common, no recent study has investigated their prevalence in bvFTD patients.

Interestingly, antisocial behavior, impulse control disorder, and cognitive and personality impairment are symptoms that may bring bvFTD patients to legal consequences. In this respect, a recent investigation reported that $14 \%$ of patients with bvFTD were initially admitted into psychiatric care due to criminal behaviors [25], highlighting the importance of considering bvFTD in the differential diagnosis even in forensic patients presenting with progressive worsening of cognitive function as well as in patients with new-onset criminal behavior [26].

A previous diagnosis of psychiatric disorders might be present in patients who subsequently develop bvFTD. In this respect, Gossink and colleagues reported a rate of $8.7 \%$ of past psychiatric disorders, with unipolar mood disorders being the most prevalent in patients with FTD [27].

\section{Diagnostic criteria and related issues}


Diagnostic criteria of bvFTD are based on the consensus criteria published in 2011 by the International behavioral Variant FTD Criteria Consortium (FTDC) [28]. These criteria stratify bvFTD diagnosis hierarchically into three categories: possible, probable and definite. According to these criteria, possible bvFTD is diagnosed based exclusively on observation or history (three out of six clinically discriminating features) that prove a progressive deterioration of behavior or cognition or both, probable is associated with imaging results consistent with bvFTD (i.e., frontal or anterior temporal atrophy on MRI or hypometabolism on PET), and definite bvFTD is supported by neuropathological data (histopathologic evidence of FTD hallmarks) or the presence of a known pathogenic mutation [28].

The fifth edition of the DSM-5 also includes diagnostic criteria for bvFTD within a new classification system for cognitive disorders [29]. Briefly, DSM-5 collects 13 etiological subtypes of acquired primary cognitive disorders, referred to as Neurocognitive Disorders (NCDs) in the same group, further subdivided into Mild or Major NCD. All patients with NCD must exhibit cognitive impairment as a core feature of their respective syndrome. Mild and Major Frontotemporal NCD is included in this chapter: however, only possible and probable diagnoses are specified. Table 1 (adapted from Lanata and Miller [10]) compares both the FTDC and DSM-5 bvFTD criteria.

Some Authors underlined a possible bias of the new DSM-5 diagnostic criteria that may inadvertently discourage recognition of bvFTD in mental health settings [10]. Specifically, DSM-5 classification relies exclusively on clinical phenotypic profiles rather than on neuroimaging and genetic tests to ascertain the correct diagnosis, which might be difficult considering the important phenotypic overlap between patients with early bvFTD and those with primary psychiatric disorders. Additionally, cognitive impairment is a core feature of bvFTD even though it may be missed, as marked cognitive changes are not necessarily present in the earliest stages of the disease 
[10]. Lastly, the DSM-5 does not include a definite bvFTD diagnostic category even in case of FTLD-causative genetic mutation, therefore marking it as probable bvFTD. In practice, this factor may lead psychiatrists and other physicians to conclude that a bvFTD cannot be diagnosed definitively antemortem with, consequently, no real reason to pursue the correct diagnosis and workup, when, in fact, definite bvFTD might be diagnosed with genetic testing [10]. In the proposed classification of the $11^{\mathrm{TH}}$ revision of the International Classification of Diseases [30], FTD defines a group of primary neurodegenerative disorders primarily affecting the frontal and temporal lobes which can be further specified in accordance to the presence of behavioural or psychological disturbances (e.g. psychotic, mood, anxiety symptoms).

\section{Clinical characteristics orienting differential diagnosis}

A careful collection of patient's history and a thorough clinical evaluation are the main instruments to make a bvFTD diagnosis $[14,31]$. Nonetheless, a correct diagnosis is not always easy to obtain because of different aspects that go beyond the simple occurrence of psychiatric symptoms in bvFTD. In fact, patients with psychiatric disorders develop dementia more often than is expected in other populations and subjects with FTD may have experienced previous psychiatric disorders before the onset of FTD [7,27]. Moreover, symptoms can be subtle and slightly defined in the early stages, showing features that are traditionally considered psychiatric manifestations. Patients with bvFTD are often first evaluated in general psychiatric settings, and about $50 \%$ of them are initially diagnosed with a primary psychiatric illness [32].

Previously, we reported a diagnostic algorithm that could help clinicians to make a correct differential diagnosis [7]. The most relevant clinical characteristics that support the diagnosis of a psychiatric disorder are an early acute/subacute onset, a positive family history of mood disorders, a history of multiple mood episodes, the presence of comorbidity (anxiety and substance use 
disorders), suicidal ideation and previous suicide attempts, inter-episodic complete or partial recovery and cognitive impairment mostly limited to affective episodes. On the other hand, a later/ insidious onset, a positive family history for dementia, a progressive and continuous course, the presence of enduring and progressive cognitive impairment, genetics and neuroimaging evidence, and a poor response to psychiatric treatments support the diagnosis of bvFTD [7].

Several recent studies have continued to analyse this sample of patients in order to understand if specific symptoms selectively characterize bvFTD or psychiatric disorders.

In a recent prospective study, Gossink and colleagues focused on psychotic symptoms in patients with bvFTD compared to patients with different primarily psychiatric disorders, assessed by the Positive and Negative Symptom Scale [27]. Of note, the majority of patients suffered from at least one psychotic symptom (95.5\%). In particular, compared to psychiatric patients, bvFTD subjects exhibited stereotypical thinking and difficulties in abstract thinking more frequently, with no difference in respect to positive symptoms [14]. Despite FTD being frequently misdiagnosed as schizophrenia (SCZ), it rarely manifests with delusions and hallucinations, as reported in previous studies [33-35]. Therefore, this result could help in the differential diagnosis. On the other hand, in the same study, patients with psychiatric disorders revealed a higher rate of symptoms belonging to the anxiety spectrum, measured by the PANSS scale (presence of anxiety, guilt feelings, and tension) [27].

In clinical practice, the presence of negative symptoms - in particular alterations in the cognitive functions - are maybe the most difficult obstacle in making a correct diagnosis.

Using a research battery designed to test 16 different cognitive domains, Hui-Minn and colleagues compared bvFTD patients with inpatients with severe chronic SCZ and community-dwelling outpatients with less severe chronic SCZ. Similarly, severe cognitive deficits were found in patients who had poorly functioning chronic SZC and those with bvFTD, higher than in patients with a 
milder form of SCZ [36]. While the overall profiles were largely similar, the SCZ group scored worse in confrontation naming and non-verbal reasoning, whereas the bvFTD group was more impaired in letter fluency and immediate memory [36].

General and frontal cognitive functioning, social cognition, and stereotyped behavior were examined in bvFTD compared with primary psychiatric disorders in a two-year follow-up investigation [37]. As a result, frontal behavioral symptoms (e.g., disinhibition, apathy) worsened over time in bvFTD, whereas they improved in psychiatric disorders. Moreover, general and frontal cognitive decline was observed in bvFTD but not in psychiatric disorders, with no differences in stereotypy and social cognition [37]. Overall, the authors proposed that tracking frontal behavioral symptoms and cognition over time might help in correctly differentiating bvFTD from psychiatric disorders.

Another recent study, controversially, reported that cognitive deficits in bvFTD were not more severe compared to those of patients with primary psychiatric disorders with active symptoms (including patients with BD, major depressive disorder, and SCZ) [38]. In particular, a better performance on executive functions and verbal memory emerged in bvFTD patients and, in contrast, bvFTD was associated with worse performance on verbal fluency tests only compared to BD [38]. Clinically, these results indicate that cognitive impairment measured with neuropsychological tests might sometimes help, in ruling out primary psychiatric diagnoses, and that further studies are needed to clarify the role of cognitive deficits.

Catatonia, a clinical presentation classically associated with SCZ, is nowadays considered a specifier applicable to different psychiatric and neurological disorders (DSM-5) and could be described as a manifestation in FTD patients. Some symptoms such as stereotypy, echophenomena, mutism, and perseveration arise both in bvFTD and in catatonia [39-42]. Moreover, some case series reported catatonia as the first clinical presentation in FTD patients [43,44]. In one interesting 
case report, authors reported catatonia in psychiatric disorders as being more frequently characterized by a fluctuating trend and usually responding to Lorazepam. In contrast, when catatonia was present in bvFTD, progressive and irreversible deterioration were more common [41]. Overall, in order to differentiate bvFTD from SCZ, the longitudinal course of the disease must be studied. While SCZ tends to manifest in adolescence, the onset of bvFTD before the age of 35 is usually uncommon. Moreover, neurodegeneration in bvFTD is progressive, while psychotic disorders are characterized by the repetition of exacerbations and asymptomatic/more stable phases $[11]$.

Another recent prospective investigation, aimed at exploring characteristics more frequently associated with bvFTD or psychiatric disorders, included patients with a diagnosis of late-onset frontal lobe syndrome. Results showed that a positive history of psychiatric illness, male gender, depressive symptoms, and absence of stereotypy were more frequently associated with psychiatric diagnoses. However, patients with bvFTD showed a higher rate of verbal apraxia, aphasia, impulsivity without irritability, and uncommon calmness and apathy [14]. Once again, in daily clinical practice, specific profiling of clinical symptoms may help in differentiating bvFTD patients from psychiatric patients, and may provide guidance in patient management.

A recent review specifically focused on shared clinical and molecular mechanisms between BD and FTD [45]. According to this investigation, these two subgroups presented similar and diverse characteristics. In particular, BD patients were found to have an earlier age at onset with a course of illness typically influenced by affective phases, while individuals with FTD tend to show a fast progression of the disease. Moreover, inflammation and neurotrophic factors were investigated, with specific pathophysiological pathways involved in these disorders. The authors proposed a hypothetical model of shared mechanisms between bvFTD and BD that includes specific Mendelian mutations (e.g. GRN, c9orf72) with genetic predisposition (e.g. brain-derived neurotrophic factor- 
BDNF gene) and environmental factors (e.g. aging, unhealthy habits) with an effect on cellular homeostasis (e.g. increased cell deaths, decreased synthesis of synaptic proteins) and an influence over behavioural and cognitive symptoms [45].

Even though the reported studies seem to support the idea that a differential diagnosis is a real issue for clinicians, other authors underscore an opposing trend contending that the presence of formal psychiatric disorders in bvFTD is not overrepresented [27]. In a recent 2-year longitudinal study, following a correct application of DSM-IV and ICD-10 criteria, the overall frequency of psychiatric disorders in probable bvFTD patients (21.7\%) did not differ from patients with other neurodegenerative diseases or possible bvFTD. An accurate application of diagnostic criteria for psychiatric disorders was proposed by the authors as a successful method for making a correct diagnosis reducing, in this way, the rate of psychiatric misdiagnosis in bvFTD [27].

\section{Possible new clinical diagnostic instruments}

In order to help practitioners make the correct differential diagnosis, new possible instruments have been proposed alongside with historical and clinical evaluation.

Ducharme and colleague recently proposed a new clinical tool to help clinicians differentiate bvFTD from other psychiatric disorders. Through a literature review, the authors developed a checklist of clinical features differentiating bvFTD from primary psychiatric disorders (PPD). The checklist contained 17 items and was then piloted, prospectively and retrospectively, in two cohorts of patients presenting with behavioral changes suggestive of bvFTD whose diagnosis was confirmed after the follow-up. As a result, a score of $\geq 11$ was found to be strongly indicative of bvFTD, while a score of $\leq 8$ was strongly indicative of a PPD. Patients with scores of 9 or 10 were considered in the "indeterminate zone" because these scores were seen across all diagnostic groups, 
including other neurocognitive disorders. This study suggested that the short checklist might be promising as a simple and useful clinical tool to improve diagnostic accuracy [46].

As previously reported, cognitive functions are broadly affected in both bvFTD and psychiatric disorders and it is not always simple to differentiate which specific domain characterizes one or the other disease. Recently, the Ekman 60 Faces, a cognitive test that specifically assesses social cognition, was proposed in this group of patients in a longitudinal multicenter study [23]. In the result, bvFTD patients obtained lower scores in the Ekman 60 Faces test compared to those with any other neurodegenerative diseases and psychiatric disorders included in the study. Other cognitive domains were not discriminative. A similar result was replicated by Chiu and colleagues who used a similar test (a novel facial emotion intensity rating task) helpful in differentiating patients with bvFTD and major depression, confirming different emotion processing paradigms between the two groups of patients [47]. On the other hand, Reus and colleagues found no difference in social cognition between bvFTD and primary psychiatric patients in social cognitive functioning [37]. These studies underlie the need for more original studies and literature metaanalysis to clarify the utility of specific neuropsychological examinations in the diagnostic procedure of bvFTD.

Other psychometric scales have shown some utility in differentiating patients with bvFTD and psychiatric disorders. In recent studies, a low Stereotypy Rating Inventory (SRI) score [48,49] and a high Montgomery-Asberg Depression Scale (MADRS) score were predictive for a psychiatric disorder compared to bvFTD [49]. Moreover, less stereotypy (based on a low score on the SRI), and more depressive symptoms (based on high scores on the MADRS) associated with male gender were found to have a good predictive ability in discriminating psychiatric disorders versus probable/ definite bvFTD in a cohort of patients with late-onset behavior changes [50]. In another investigation, the PANSS total score of the negative subscale was significantly higher in patients 
with bvFTD than in patients with a psychiatric disorder, while the PANSS total score of positive subscale was not different [27].

Interestingly, cerebrospinal fluid (CSF) examination was proposed as a potential diagnostic tool to help in the differential diagnosis [51]. CSF has a great diagnostic value in the diagnosis of dementia, especially in Alzheimer's disorder [52], and it was proposed to use this procedure to differentiate patients with bvFTD and primary psychiatric disorders. As a result, the CSF levels of three biomarkers involved in the pathophysiology of FTD - NfL (neurofilament light chain), p-tau/ tau ratio (phosphorylated-tau to total-tau ratio), and YKL40 (chitinase-3 like-1, cartilage glycoprotein-39) - were found to be the best discriminators between the two groups of disorders, with a sensitivity of $91 \%$ and specificity of $83 \%$ considering the combination of these three biomarkers. In fact, higher levels of CSF NfL and YKL40 and reduced p-tau/tau ratio have shown good accuracy in distinguishing bvFTD from psychiatric disorders and will potentially become in the the future suitable biomarkers [51]. Following the neuropathological perspective of the abovementioned study, another recent investigation measured the levels of NfL in a blood sample. As a result, serum NfL levels were significantly elevated in bvFTD patients compared to the controls (depressed, schizophrenic and bipolar patients [53]), proposing NfL serum as a possible biomarker in differentiating bvFTD from psychiatric disorders and as a method to rule out neurodegeneration in the course of psychiatric disorders.

\section{New neuroimaging insights}

Neuroimaging plays an important role in the diagnosis of bvFTD. A probable diagnosis of bvFTD can be made considering specific brain abnormalities consistently related with bvFTD, specifically in the fronto-insular and temporal cortices, dorsomedial prefrontal cortex, striatum, and thalamus [54,55]. Moreover, neuroimaging studies have given a considerable contribution to the 
understanding of the neuropathology of FTD and even in the differential diagnosis between psychiatric disorders.

In this respect, Baez and colleagues recently compared subjects with late-onset BD and bvFTD in terms of neuropsychological and neuroanatomical assessment using voxel-based morphometry. Compared to BD, bvFTD patients exhibited a significant decrease in gray matter (GM) volume in frontal, temporal and parietal regions. From a neuropsychological perspective, atrophy in specific brain regions were associated with specific cognitive impairments in bvFTD compared with BD patients. In the former group, atrophy of frontal, temporal and insular cortices was related to executive functioning deficits. Moreover, atrophy of the amygdala, hippocampus, parahippocampal gyrus, putamen, insula, precuneus, right temporo-parietal junction and superior temporal pole was associated with the theory of mind impairments. No significant associations between atrophy and executive functioning performance were observed in $\mathrm{BD}$ patients [56]. These results seem to provide additional evidence to discriminate bvFTD and late-life BD as distinct clinical entities and support the use of neuropsychological and structural imaging assessments for the differential diagnosis.

Interestingly, an MRI based investigation found that right anterior temporal atrophy and sparing of the left frontal lobe were specifically associated with bvFTD patients with psychotic-like speech (i.e pressure of speech, tangentiality, derailment, clanging/rhyming, and punning) in the absence of other psychotic symptoms [33].

Additionally, positron emission tomography scans have shown a role in differentiating bvFTD from other forms of dementia [57,58]. Late-onset BD and bvFTD patients were also assessed and compared with MRI and PET, reporting structural and functional different abnormalities [59]. More specifically, BD patients showed grey matter reduction in the ventrolateral prefrontal cortex and greater grey matter volumes in the caudate nucleus. On the other hand, bvFTD patients reported 
grey matter reductions in the dorsolateral prefrontal cortex and volumetric and metabolic reductions within the orbitofrontal cortex, volumetric shrinkage in regions within the temporo-parietal network as well as greater metabolic impairments within the temporal cortex, more extensive volumetric and metabolic abnormalities within the limbic lobe, and lastly, a greater metabolism in caudate nucleus. Finally, while the BD group showed greater grey matter volumes in the caudate nucleus, bvFTD subjects reported a lower metabolism [59].

Additionally, a recent investigation identified how specific neuroanatomical abnormalities (analyzed through voxel-based morphometry) correlated with psychiatric symptoms in patients carrying a gene mutation suggestive of bvFTD [60]. As a result, the main forms of genetic FTD showed distinct neuroanatomical correlations with neuropsychiatric symptoms (i.e. strong association of psychotic symptoms with GM atrophy in the anterior insula for the group with GRN mutation; presence of mood disorders mostly associated with GM atrophy in frontal-insular cortex for the group with GRN mutation; cerebellar atrophy found to only correlate with anxiety in C9orf72 carriers; delusions in C9orf72 expansion carriers prevalently associated with left frontal cortical atrophy). Overall, these findings support the concept of brain structural changes overlapping between FTD and primary psychiatric disorders that may be mediated by the alteration of common genes relevant in structures involved in large-scale networks [60].

More recently, a combination of neuroimaging data and clinical information collected at baseline has been used in machine learning algorithms in order to predict two-year follow-up diagnosis in patients with bvFTD, psychiatric disorders, and other neurological disorders. This technique demonstrated a good accuracy in distinguishing bvFTD from other neurological disorders and psychiatric disorders in particular [48]. Therefore, this machine-learning algorithm might be a future valuable instrument for clinicians to obtain an early and accurate diagnosis [48]. 


\section{New research in genetics}

Genetics play an important role in the neuropathology of bvFTD: up to 50\% of patients have a positive family history of dementia [19] and approximately one third of FTD cases has a known genetic cause, supporting the assumption that this disorder might be highly heritable [21]. Moreover, they also have an important role in the diagnosis because, according to FTDC criteria, a genetic test can lead to an ante mortem definite bvFTD diagnosis.

Neuropsychiatric symptoms are quite common in FTD related mutation carriers [60], underlining the overlap between FTD and psychiatric disorders in terms of neuropathology. In our previous report, we already listed the most common genetic mutations related to this condition. Briefly, the most prevalent mutations associated with familial FTD are a repeated expansion of an intronic hexanucleotide (GGGGCC) in the chromosome 9 open reading frame 72 (C9orf72) gene ( 30\%), followed by mutations in the genes for progranulin (GRN 20\%) and microtubule-associated protein tau (MAPT, 10\%). Psychiatric symptoms are frequently present in C9orf72 carriers and, to a lesser extent, in GRN carriers [45]. Less frequent mutations include Valosin-containing protein (VCP), charged multivesicular body protein 2B (CHMP2B), ubiquilin 2 (UBQLN2), sequestosome 1 (SQSTM1), TAR DNA binding protein (TARDBP) and fused RNA binding protein (FUS) $[7,61,62]$.

In order to better clarify the etiology of this heterogeneous disorder and its relationship to neuropsychiatric symptoms, recent gene investigations analyzed the association between genetics and clinical course of the illness. The C9orf72 mutation consists of a repeated expansion of a hexanucleotide (GGGGCC) in the first intron of the gene, which shows an autosomal dominant pattern of inheritance. Studies have shown a relatively strict correlation between C9ORF72 expansion and the presence of neuronal inclusions containing TAR DNA binding protein (TDP-43) on neuropathological examination [61]. In terms of clinical presentation, patients with a C9orf72 
expansion typically present with bvFTD, a motorneuron disease (MND) or a combination of both $[7]$.

As far as cognitive functioning is concerned, patients often show a decline in visual and verbal episodic memory, apraxia, anomia, dyscalculia, and reduced spontaneous speech. On the other hand, language seems to be impaired less frequently than in patients with GRN or MAPT mutations [61]. Neuropsychiatric symptoms like somatic delusions and, more broadly, psychotic symptoms are more common in $\mathrm{C} 9$ orf72 carriers than in non-carriers, while the rate of hallucinations does not seem to differ between the two groups $[63,64]$. In a case series, Shinagawa and colleagues described how C9orf72 carriers with well-defined delusions were likely associated with additional pathologies (i.e. Parkinsonism) and parietal atrophy in neuroimaging, underling a common neurophathology between FTD and delusion [65]. Affective symptoms, anxiety, suicidal behavior, and obsessive-compulsive disorder may be present as well $[7,19,66]$.

Another gene often associated with FTD is progranulin (GRN), whose frameshift and non-sense mutations result in the reduction of circulating levels of progranulin, a glycoprotein involved in lysosomal functions, neurite growth, synaptic transmission and neuroinflammation [62]. Autosomal dominant, with variable penetrance, is the typical pattern of inheritance [7]. FTD patients with progranulin mutations often present as bvFTD or, less frequently, with progressive PPA. Typical clinical presentation features are apathy and social withdrawal, and in a minority of cases, episodic memory impairment. In regards to neuropsychiatric symptoms, delusions, hallucinations and ritualistic behaviors may be present. Of note, an early language impairment is more frequent compared with cases with C9orf72 or MAPT mutations. The frequency of extrapyramidal symptoms stands around 40-60\% [61].

Interestingly, a reduction of progranulin was detected not only in bvFTD but in BD as well. In a recent article, Zanardini reported that an imbalanced expression of this neurotrophin in specific 
brain regions and in different periods of life might result in either neurodegenerative or psychiatric diseases. Moreover, subjects with progranulin deficit might present with psychiatric symptoms that could represent a preclinical phase preceding FTD [67,68]. Consistently, a recent case report documented a case of late-onset BD that developed into bvFTD over time in a patient carrying a GRN mutation [69]. Ultimately, studies suggest a close relationship between manic behavior and bvFTD, even though the nature of this correlation is still unclear and needs to be explored in further investigation [68].

The MAPT gene encodes the microtubule-associated protein Tau, which is involved in microtubule stabilization and assembly. Research studies have allowed the identification of more than 40 mutations of MAPT, involving different areas of the gene and variably affecting tau function. These mutations interfere with protein function by promoting tau aggregation, hindering microtubule binding and altering isoforms ratio [7]. The pattern of inheritance is autosomal dominant, with high penetrance. From an anatomo-pathological perspective, patients typically present with tau-positive inclusions (FTLD- Tau) [7].

The clinical features of patients with MAPT-associated FTD are heterogeneous with regard to both symptoms and age of onset [7]. An interesting recent case report analyses an Argentinean family with a family history of bvFTD with an autosomal dominant pattern of inheritance, including one sibling diagnosed with Cortico-Basal Syndrome (CBS) and another one with FTD. Researchers found a missense mutation (p.P301L) in exon 10 of the MAPT gene in both affected siblings. Among MAPT mutations, p.P301L is most often associated with the following clinical syndromes: early-onset Parkinsonism, late Parkinsonism associated with FTD, Progressive Supranuclear Palsy (PSP) and, exceptionally, CBS. This report highlights the marked phenotypic heterogeneity not only among unrelated individuals but also within the same family [70]. With respect to psychiatric symptoms, the most common features of MAPT-associated FTD include disinhibition, poor impulse 
control, loss of insight, stereotyped repetitive behaviors, obsessions, mental rigidity and lack of social awareness or context, whereas apathy is less common than in PGRN and C9orf72 cases. Mood and anxiety disorders, on the other hand, seem less common in patients with MAPT mutation, except for depressive disorder not otherwise specified, an atypical syndrome characterized by clinically significant depressive symptoms, which fail to meet criteria for major depressive disorder [71]. Other clinical features include episodic memory loss, which might lead to the diagnosis of early onset Alzheimer's disease (AD) and semantic impairment, which often appears later during the course of the disease [61].

Ultimately, Gotovak and colleagues highlighted a new correlation between the APOE e4 allele and aggressive symptoms in FTD [72].

Even though the above-mentioned mutations seem to play a key role in the etiopathogenesis of the disorder, most FTD cases are the result of complex - and yet to be fully understood - interactions between genetic, epigenetic and environmental factors. BvFTD must, therefore, be considered a multifactorial disease. Nevertheless, clinicians should be able to apply current evidence about genetics in clinical practice and hypothesise a genetic etiology when taking patients with FTD into consideration. A family history dating back to three generations should be carefully investigated with a focus on the neuropsychiatric symptoms, and if a familial form of the disorder is suspected, both the patient and the family should be referred to genetic counselling [16]. In this respect, genetic testing should be considered in patients with FTD and a strong family history of autosomal dominant neurological disorders including FTD, AD, Parkinsonism, MND, inclusion body myopathy, or late-onset psychosis with insidiously worsening course [18,73].

\section{Possible new therapeutic approaches and disease prognosis}


Alongside the complexity of the clinical presentation and the difficulties encountered in making the correct differential diagnosis, the therapeutic approach is a challenging issue for clinicians.

To date, there are no United State Food and Drug Administration (FDA) approved therapies for FTD, and there are no treatments that can stop or alter the course of disease progression [74]. Thus, medication typically prescribed for other types of dementia and psychiatric syndromes are frequently used as off-label treatments for FTD [75]. This could mainly be due to the paucity of large, double blind, randomized controlled trials with the available knowledge of therapeutic strategies mainly based on small case series [74]. The majority of treatment intervention is aimed at obtaining symptomatic relief (improving behavioral, cognitive, or motor symptoms) by using a variety of agents with mixed results in terms of efficacy [74].

Currently, the treatment for cognitive symptoms is based on acetylcholinesterase inhibitors (e.g. donepezil, galantamine, rivastigmine). No consistent data on improvement is reported in literature, with some investigation reporting that acetylcholinesterase inhibitors may worsen behavioral disturbances in FTD [76]. Memantine, an NMDA-antagonist, has been proposed as an alternative therapy in FTD; however it currently lacks clear therapeutic benefits [77].

Considering the high prevalence of patients with psychiatric symptoms, current FTD pharmacologic strategies have specifically focused on the modulation of behavioral symptoms. These medications include a variety of antidepressant effects that could target both depressive symptoms (such as apathy and abulia) and aggressiveness, irritability, disinhibition, and delusions [61]. Among these drugs, some reports supported the use of selective serotonin reuptake inhibitors (such as citalopram, paroxetine, sertraline), and serotonin modulators (trazodone) [78] and the dopamine-norepinephrine reuptake inhibitor bupropion [79]. Agomelatine, but not melatonin, was associated with a significant reduction of apathy in FTD subjects [80]. 
While antipsychotics have long been used to control behavioral alterations, evidence for their use in FTD comes mainly from case reports and uncontrolled series [81]. Pharmacological approaches aimed to control behavioral symptoms involve the use of atypical antipsychotics (quetiapine, risperidone, aripiprazole, olanzapine) and of anti-epileptics with mood stabilizing effects such as valproic acid, topiramate and carbamazepine. For these pharmacological compounds, the effects are variable and evidence is mostly limited to case reports as well [76]. Additionally, antipsychotic use is often associated with severe adverse effect profiles. Of note, there is an increased susceptibility to extrapyramidal symptoms after antipsychotic use in patients with FTD [82].

Alongside the pharmacological approach, non-pharmacological interventions are considered along with pharmacological therapies. These interventions include providing caregivers with information, emotional support, strategies for behavioral management, and access to community resources with the aim to support the patient and to reduce the high burden of distress perceived by caregivers $[8,24,61]$. A multidisciplinary team approach involving physicians (neurologists and psychiatrists), nursing, physical therapy, and other rehabilitative services, as well as social work and caregiver/ family involvement, is often required for the optimal management of patients with psychiatric disorders in dementia [6].

The difficult therapeutic management, alongside the difficulties in the differential diagnosis, have a dramatic impact on the prognosis of this disorder. The survival time of patients affected with FTD is usually 2 to 11 years from symptoms onset [21,83]. According to Lee et al., the prognosis of patients with bvFTD varies according to the extent of atrophy of the frontal lobe visible at the MRI. In fact, in their study, the survival time was shorter in patients with bvFTD who show diffuse frontal lobe atrophy (6.9 years) than in bvFTD patients with focal or circumscribed frontal lobe atrophy (9.4 years) on MRI [84]. Considering that diagnosis is often delayed, the survival time after diagnosis is only 4 years for bvFTD. Moreover, a low prognosis could have been associated to a 
high prevalence of suicidal risk in this population, which is particularly high in younger patients with longer illness duration and associated to higher levels of anxiety and depression [85]. Additionally, the diagnosis of FTD as a single or comorbid condition with other psychiatric disorders significantly worsens the general prognosis [6,7]. Other characteristics associated with a worse prognosis include a shorter disease duration at presentation, a greater atrophy in the anterior cingulate cortex, an older age, and a higher burden of behavioral symptoms [83].

Lastly, a known pathogenic frontotemporal dementia mutation was reported as being the strongest predictor of disease progression [83]. However, no prognostic markers are available and predicting the course of the disease for a singular patient remains difficult [18-20].

\section{Conclusions}

Table 2 summarizes the most recent findings (post 2015) that may be helpful in differentiating bvFTD from primary psychiatric disorders. In conclusion, FTD comprises different expressions of pathology, which may pose significant challenges to clinicians for differential diagnosis with primary psychiatric disorders, particularly for bvFTD. While imaging and genetic characterization can help to orient clinicians toward the right diagnosis, an accurate clinical investigation with particular attention to family history, age at onset, previous subclinical episodes, type of course and comorbidity patterns, still remains the most useful approach to obtain a correct diagnosis in clinical practice. While a robust body of evidence is now available in the field, many clinicians do not operate in team and delayed/misdiagnosis with unsuccessful treatments represent the most frequent consequences of such an approach. Even though effective treatments for bvFTD are currently lacking, symptomatic interventions may still prove useful for affected patients, while supportive interventions of pharmacological and psychotherapeutic nature may be helpful not only for patients but for their caregivers as well. 


\section{ACKNOWLEDGMENTS AND DISCLOSURES}

Prof. Dell'Osso has received Grant/Research Support from LivaNova, Inc., Angelini and Lundbeck and Lecture Honoraria from Angelini, FB Health and Lundbeck. Dr. Vismara, Dr. Cirnigliaro, Dr. Piccoli, Dr. Molteni, Dr. Giorgetti, Dr. Fumagalli, Dr. D’addario, and Dr. Cremaschi report no potential conflict of interest. 


\section{REFERENCES}

[1] Hodges JR (2001) Frontotemporal dementia (Pick’s disease): clinical features and assessment. Neurology 56, S6-10.

[2] Neary D, Snowden JS, Gustafson L, Passant U, Stuss D, Black S, Freedman M, Kertesz A, Robert PH, Albert M, Boone K, Miller BL, Cummings J, Benson DF (1998) Frontotemporal lobar degeneration: a consensus on clinical diagnostic criteria. Neurology 51, 1546-54.

[3] Mocellin R, Scholes A, Walterfang M, Looi JC, Velakoulis D (2015) Clinical update on frontotemporal dementia: diagnosis and treatment. Australas. Psychiatry 23, 481-487.

[4] Gorno-Tempini ML, Dronkers NF, Rankin KP, Ogar JM, Phengrasamy L, Rosen HJ, Johnson JK, Weiner MW, Miller BL (2004) Cognition and anatomy in three variants of primary progressive aphasia. Ann. Neurol. 55, 335-346.

[5] Park MH, Kim E-J, Park KW, Kwon JC, Ku BD, Han S-H, Kim S, Yang DW, Na DL, Choi SH (2017) Behavioural and neuropsychiatric disturbance in three clinical subtypes of frontotemporal dementia: A Clinical Research Center for Dementia of South Korea-FTD Study. Australas. J. Ageing 36, 46-51.

[6] Onyike CU (2016) Psychiatric Aspects of Dementia. Contin. Lifelong Learn. Neurol. 22, $600-614$.

[7] Galimberti D, Dell’Osso B, Altamura AC, Scarpini E (2015) Psychiatric Symptoms in Frontotemporal Dementia: Epidemiology, Phenotypes, and Differential Diagnosis. Biol. Psychiatry 78, 684-692.

[8] Seeley WW (2019) Behavioral Variant Frontotemporal Dementia. Contin. Lifelong Learn. Neurol. 25, 76-100.

[9] Olney NT, Spina S, Miller BL (2017) Frontotemporal Dementia. Neurol. Clin. 35, 339-374.

[10] Lanata SC, Miller BL (2016) The behavioural variant frontotemporal dementia (bvFTD) 
syndrome in psychiatry. J. Neurol. Neurosurg. Psychiatry 87, 501-511.

[11] Ducharme S, Price BH, Larvie M, Dougherty DD, Dickerson BC (2015) Clinical Approach to the Differential Diagnosis Between Behavioral Variant Frontotemporal Dementia and Primary Psychiatric Disorders. Am. J. Psychiatry 172, 827-837.

[12] Tondo G, De Marchi F, Terazzi E, Sacchetti M, Cantello R (2017) Frontotemporal Dementia Presenting as Gambling Disorder. Cogn. Behav. Neurol. 30, 62-67.

[13] Papazacharias A, Lozupone M, Barulli MR, Capozzo R, Imbimbo BP, Veneziani F, De Blasi R, Nardini M, Seripa D, Panza F, Logroscino G (2016) Bipolar Disorder and Frontotemporal Dementia: An Intriguing Association. J. Alzheimer's Dis. 55, 973-979.

[14] Dols A, van Liempt S, Gossink F, Krudop WA, Sikkes S, Pijnenburg YAL, Stek ML (2016) Identifying Specific Clinical Symptoms of Behavioral Variant Frontotemporal Dementia Versus Differential Psychiatric Disorders in Patients Presenting With a Late-Onset Frontal Lobe Syndrome. J. Clin. Psychiatry 77, 1391-1395.

[15] World Health Organization (2015) The prevalence of dementia worldwide.

[16] Rosness TA, Engedal K, Chemali Z (2016) Frontotemporal Dementia. J. Geriatr. Psychiatry Neurol. 29, 271-280.

[17] Logroscino G, Piccininni M, Binetti G, Zecca C, Turrone R, Capozzo R, Tortelli R, Battista P, Bagoj E, Barone R, Fostinelli S, Benussi L, Ghidoni R, Padovani A, Cappa SF, Alberici A, Borroni B (2019) Incidence of frontotemporal lobar degeneration in Italy. Neurology 92 , e2355-e2363.

[18] Bang J, Spina S, Miller BL (2015) Frontotemporal dementia. Lancet (London, England) 386, 1672-82.

[19] Waldö ML (2015) The Frontotemporal Dementias. Psychiatr. Clin. North Am. 38, 193-209.

[20] Hogan DB, Jetté N, Fiest KM, Roberts JI, Pearson D, Smith EE, Roach P, Kirk A, 
Pringsheim T, Maxwell CJ (2016) The Prevalence and Incidence of Frontotemporal

Dementia: a Systematic Review. Can. J. Neurol. Sci. / J. Can. des Sci. Neurol. 43, S96-S109.

[21] Coyle-Gilchrist ITS, Dick KM, Patterson K, Vázquez Rodríquez P, Wehmann E, Wilcox A, Lansdall CJ, Dawson KE, Wiggins J, Mead S, Brayne C, Rowe JB (2016) Prevalence, characteristics, and survival of frontotemporal lobar degeneration syndromes. Neurology 86, $1736-1743$.

[22] Hall D, Finger EC (2015) Psychotic Symptoms in Frontotemporal Dementia. Curr. Neurol. Neurosci. Rep. 15, 46.

[23] Gossink FT, Vijverberg EG, Krudop W, Scheltens P, Stek ML, Pijnenburg Y AL, Dols A (2017) Psychosis in behavioral variant frontotemporal dementia. Neuropsychiatr. Dis. Treat. Volume 13, 1099-1106.

[24] Lima-Silva TB, Bahia VS, Carvalho VA, Guimarães HC, Caramelli P, Balthazar ML, Damasceno B, Bottino CM, Brucki SM, Nitrini R, Yassuda MS (2015) Neuropsychiatric Symptoms, Caregiver Burden and Distress in Behavioral-Variant Frontotemporal Dementia and Alzheimer's Disease. Dement. Geriatr. Cogn. Disord. 40, 268-275.

[25] Liljegren M, Naasan G, Temlett J, Perry DC, Rankin KP, Merrilees J, Grinberg LT, Seeley WW, Englund E, Miller BL (2015) Criminal Behavior in Frontotemporal Dementia and Alzheimer Disease. JAMA Neurol. 72, 295.

[26] Birkhoff JM, Garberi C, Re L (2016) The behavioral variant of frontotemporal dementia: An analysis of the literature and a case report. Int. J. Law Psychiatry 47, 157-163.

[27] Gossink FT, Dols A, Krudop WA, Sikkes SA, Kerssens CJ, Prins ND, Scheltens P, Stek ML, Pijnenburg YAL (2016) Formal Psychiatric Disorders are not Overrepresented in Behavioral Variant Frontotemporal Dementia. J. Alzheimer's Dis. 51, 1249-1256.

[28] Rascovsky K, Hodges JR, Knopman D, Mendez MF, Kramer JH, Neuhaus J, van Swieten JC, 
Seelaar H, Dopper EGP, Onyike CU, Hillis AE, Josephs KA, Boeve BF, Kertesz A, Seeley WW, Rankin KP, Johnson JK, Gorno-Tempini M-L, Rosen H, Prioleau-Latham CE, Lee A, Kipps CM, Lillo P, Piguet O, Rohrer JD, Rossor MN, Warren JD, Fox NC, Galasko D, Salmon DP, Black SE, Mesulam M, Weintraub S, Dickerson BC, Diehl-Schmid J, Pasquier F, Deramecourt V, Lebert F, Pijnenburg Y, Chow TW, Manes F, Grafman J, Cappa SF, Freedman M, Grossman M, Miller BL (2011) Sensitivity of revised diagnostic criteria for the behavioural variant of frontotemporal dementia. Brain 134, 2456-2477.

[29] American Psychiatric Association., American Psychiatric Association. DSM-5 Task Force. (2013) Diagnostic and statistical manual of mental disorders : DSM-5., American Psychiatric Association, Arlington VA ;Washington D.C.

[30] ICD-11 - Mortality and Morbidity Statistics, Last updated 2019, Accessed on 2019.

[31] Krudop WA, Dols A, Kerssens CJ, Eikelenboom P, Prins ND, Möller C, Schouws S, Rhebergen D, van Exel E, van der Flier WM, Sikkes S, Scheltens P, Stek ML, Pijnenburg YAL (2017) The Pitfall of Behavioral Variant Frontotemporal Dementia Mimics Despite Multidisciplinary Application of the FTDC Criteria. J. Alzheimer's Dis. 60, 959-975.

[32] Woolley JD, Khan BK, Murthy NK, Miller BL, Rankin KP (2011) The Diagnostic Challenge of Psychiatric Symptoms in Neurodegenerative Disease. J. Clin. Psychiatry 72, 126-133.

[33] Mendez MF, Carr AR, Paholpak P (2017) Psychotic-Like Speech in Frontotemporal Dementia. J. Neuropsychiatry Clin. Neurosci. 29, 183-185.

[34] Gregory CA (1999) Frontal variant of frontotemporal dementia: a cross-sectional and longitudinal study of neuropsychiatric features. Psychol. Med. 29, 1205-17.

[35] Passant U, Elfgren C, Englund E, Gustafson L (2005) Psychiatric Symptoms and Their Psychosocial Consequences in Frontotemporal Dementia. Alzheimer Dis. Assoc. Disord. 19, S15-S18. 
[36] Chan H-M, Stolwyk R, Neath J, Kelso W, Walterfang M, Mocellin R, Pantelis C, Velakoulis D (2015) Neurocognitive similarities between severe chronic schizophrenia and behavioural variant frontotemporal dementia. Psychiatry Res. 225, 658-666.

[37] Reus LM, Vijverberg EG, Tijms BM, Kate M ten, Gossink F, Krudop WA, Campo M del, Teunissen CE, Barkhof F, van der Flier WM, Visser PJ, Dols A, Pijnenburg YA (2018) Disease trajectories in behavioural variant frontotemporal dementia, primary psychiatric and other neurodegenerative disorders presenting with behavioural change. J. Psychiatr. Res. 104, $183-191$.

[38] Vijverberg EGB, Schouws S, Meesters PD, Verwijk E, Comijs H, Koene T, Schreuder C, Beekman A, Scheltens P, Stek M, Pijnenburg Y, Dols A (2017) Cognitive Deficits in Patients With Neuropsychiatric Symptoms. J. Clin. Psychiatry 78, e940-e946.

[39] Suzuki K, Takano T, Matsuoka H (2009) A case of catatonia resembling frontotemporal dementia and resolved with electroconvulsive therapy. World J. Biol. Psychiatry 10, 245247.

[40] Fink M, Taylor MA (2009) The Catatonia Syndrome. Arch. Gen. Psychiatry 66, 1173.

[41] Ducharme S, Dickerson BC, Larvie M, Price BH (2015) Differentiating Frontotemporal Dementia From Catatonia: A Complex Neuropsychiatric Challenge. J. Neuropsychiatry Clin. Neurosci. 27, e174-e176.

[42] Kagan J, Sewell RA, Price B et al: (2007) The differentiation of fronto-temporal dementia from catatonia in a 43-year-old woman - a case report. Ann Behav Neurol 5-10.

[43] Watanabe R, Kawakami I, Onaya M, Higashi S, Arai N, Akiyama H, Hasegawa M, Arai T (2018) Frontotemporal dementia with trans-activation response DNA-binding protein 43 presenting with catatonic syndrome. Neuropathology 38, 281-287.

[44] Holm AC (2014) Neurodegenerative and psychiatric overlap in frontotemporal lobar 
degeneration: a case of familial frontotemporal dementia presenting with catatonia. Int. Psychogeriatrics 26, 345-347.

[45] Nascimento C, Villela Nunes P, Diehl Rodriguez R, Takada L, Kimie Suemoto C, Tenenholz Grinberg L, Nitrini R, Lafer B (2019) A review on shared clinical and molecular mechanisms between bipolar disorder and frontotemporal dementia. Prog. Neuro-Psychopharmacology Biol. Psychiatry 93, 269-283.

[46] Ducharme S, Pearl-Dowler L, Gossink F, McCarthy J, Lai J, Dickerson BC, Chertkow H, Rapin L, Vijverberg E, Krudop W, Dols A, Pijnenburg Y (2019) The Frontotemporal Dementia versus Primary Psychiatric Disorder (FTD versus PPD) Checklist: A Bedside Clinical Tool to Identify Behavioral Variant FTD in Patients with Late-Onset Behavioral Changes. J. Alzheimer's Dis. 67, 113-124.

[47] Chiu I, Piguet O, Diehl-Schmid J, Riedl L, Beck J, Leyhe T, Holsboer-Trachsler E, Berres M, Monsch AU, Sollberger M (2016) Dissociation in Rating Negative Facial Emotions between Behavioral Variant Frontotemporal Dementia and Major Depressive Disorder. Am. J. Geriatr. Psychiatry 24, 1017-1027.

[48] Zhutovsky P, Vijverberg EGB, Bruin WB, Thomas RM, Wattjes MP, Pijnenburg YAL, van Wingen GA, Dols A (2019) Individual Prediction of Behavioral Variant Frontotemporal Dementia Development Using Multivariate Pattern Analysis of Magnetic Resonance Imaging Data. J. Alzheimer's Dis. 68, 1229-1241.

[49] Dols A, van Liempt S, Gossink F, Krudop WA, Sikkes S, Pijnenburg YAL, Stek ML (2016) Identifying Specific Clinical Symptoms of Behavioral Variant Frontotemporal Dementia Versus Differential Psychiatric Disorders in Patients Presenting With a Late-Onset Frontal Lobe Syndrome. J. Clin. Psychiatry 77, 1391-1395.

[50] Vijverberg EGB, Gossink F, Krudop W, Dols A, Pijnenburg YAL (2018) [Behavioural 
changes as a symptom: diagnosing behavioural variant frontotemporal dementia]. Ned. Tijdschr. Geneeskd. 162,.

[51] Vijverberg EGB, Dols A, Krudop WA, Del Campo Milan M, Kerssens CJ, Gossink F, Prins ND, Stek ML, Scheltens P, Teunissen CE, Pijnenburg YAL (2017) Cerebrospinal fluid biomarker examination as a tool to discriminate behavioral variant frontotemporal dementia from primary psychiatric disorders. Alzheimer's Dement. Diagnosis, Assess. Dis. Monit. 7 , 99-106.

[52] Lewczuk P, Riederer P, O’Bryant SE, Verbeek MM, Dubois B, Visser PJ, Jellinger KA, Engelborghs S, Ramirez A, Parnetti L, Jack CR, Teunissen CE, Hampel H, Lleó A, Jessen F, Glodzik L, de Leon MJ, Fagan AM, Molinuevo JL, Jansen WJ, Winblad B, Shaw LM, Andreasson U, Otto M, Mollenhauer B, Wiltfang J, Turner MR, Zerr I, Handels R, Thompson AG, Johansson G, Ermann N, Trojanowski JQ, Karaca I, Wagner H, Oeck1 P, van Waalwijk van Doorn L, Bjerke M, Kapogiannis D, Kuiperij HB, Farotti L, Li Y, Gordon BA, Epelbaum S, Vos SJB, Klijn CJM, Van Nostrand WE, Minguillon C, Schmitz M, Gallo C, Lopez Mato A, Thibaut F, Lista S, Alcolea D, Zetterberg H, Blennow K, Kornhuber J, Members of the WFSBP Task Force Working on this Topic: Peter Riederer, Carla Gallo, Dimitrios Kapogiannis, Andrea Lopez Mato, Florence Thibaut (2018) Cerebrospinal fluid and blood biomarkers for neurodegenerative dementias: An update of the Consensus of the Task Force on Biological Markers in Psychiatry of the World Federation of Societies of Biological Psychiatry. World J. Biol. Psychiatry 19, 244-328.

[53] Al Shweiki MR, Steinacker P, Oeckl P, Hengerer B, Danek A, Fassbender K, Diehl-Schmid J, Jahn H, Anderl-Straub S, Ludolph AC, Schönfeldt-Lecuona C, Otto M (2019) Neurofilament light chain as a blood biomarker to differentiate psychiatric disorders from behavioural variant frontotemporal dementia. J. Psychiatr. Res. 113, 137-140. 
[54] Rosen HJ, Gorno-Tempini ML, Goldman WP, Perry RJ, Schuff N, Weiner M, Feiwell R, Kramer JH, Miller BL (2002) Patterns of brain atrophy in frontotemporal dementia and semantic dementia. Neurology 58, 198-208.

[55] Seeley WW, Crawford R, Rascovsky K, Kramer JH, Weiner M, Miller BL, Gorno-Tempini ML (2008) Frontal Paralimbic Network Atrophy in Very Mild Behavioral Variant Frontotemporal Dementia. Arch. Neurol. 65, 249-55.

[56] Baez S, Pinasco C, Roca M, Ferrari J, Couto B, García-Cordero I, Ibañez A, Cruz F, Reyes P, Matallana D, Manes F, Cetcovich M, Torralva T (2019) Brain structural correlates of executive and social cognition profiles in behavioral variant frontotemporal dementia and elderly bipolar disorder. Neuropsychologia 126, 159-169.

[57] Nazem A, Tang CC, Spetsieris P, Dresel C, Gordon ML, Diehl-Schmid J, Grimmer T, Yakushev I, Mattis PJ, Ma Y, Dhawan V, Eidelberg D (2018) A multivariate metabolic imaging marker for behavioral variant frontotemporal dementia. Alzheimer's Dement. Diagnosis, Assess. Dis. Monit. 10, 583-594.

[58] Nam G, Jeong HJ, Kang JM, Lee S-Y, Seo S, Seo H-E, Park KH, Yeon BK, Ido T, Shin DJ, Noh Y (2018) 18F-THK5351 PET Imaging in the Behavioral Variant of Frontotemporal Dementia. Dement. neurocognitive Disord. 17, 163-173.

[59] Delvecchio G, Mandolini GM, Arighi A, Prunas C, Mauri CM, Pietroboni AM, Marotta G, Cinnante CM, Triulzi FM, Galimberti D, Scarpini E, Altamura AC, Brambilla P (2019) Structural and metabolic cerebral alterations between elderly bipolar disorder and behavioural variant frontotemporal dementia: A combined MRI-PET study. Aust. New Zeal. J. Psychiatry 53, 413-423.

[60] Sellami L, Bocchetta M, Masellis M, Cash DM, Dick KM, van Swieten J, Borroni B, Galimberti D, Tartaglia MC, Rowe JB, Graff C, Tagliavini F, Frisoni G, Finger E, de 
Mendonça A, Sorbi S, Warren JD, Rohrer JD, Laforcem R, Genetic FTD Initiative, GENFI

(2018) Distinct Neuroanatomical Correlates of Neuropsychiatric Symptoms in the Three

Main Forms of Genetic Frontotemporal Dementia in the GENFI Cohort. J. Alzheimer's Dis.

65, $1-16$.

[61] Young JJ, Lavakumar M, Tampi D, Balachandran S, Tampi RR (2018) Frontotemporal dementia: latest evidence and clinical implications. Ther. Adv. Psychopharmacol. 8, 33-48.

[62] Solomon DA, Mitchell JC, Salcher-Konrad M-T, Vance CA, Mizielinska S (2019) Review: Modelling the pathology and behaviour of frontotemporal dementia. Neuropathol. Appl. Neurobiol. 45, 58-80.

[63] Erzurumluoglu E, Cilingir O, Ozbabalik Adapinar BD, Bilgic B, Kocagil S, Ozen H, Durak Aras B, Yenilmez C, Artan S (2019) The association between repeat number in C9orf72 and phenotypic variability in Turkish patients with frontotemporal lobar degeneration. Neurobiol. Aging 76, 216.e1-216.e7.

[64] Devenney EM, Landin-Romero R, Irish M, Hornberger M, Mioshi E, Halliday GM, Kiernan MC, Hodges JR (2017) The neural correlates and clinical characteristics of psychosis in the frontotemporal dementia continuum and the C9orf72 expansion. NeuroImage Clin. 13, 439445.

[65] Shinagawa S, Naasan G, Karydas AM, Coppola G, Pribadi M, Seeley WW, Trojanowski JQ, Miller BL, Grinberg LT (2015) Clinicopathological Study of Patients With C9ORF72 Associated Frontotemporal Dementia Presenting With Delusions. J. Geriatr. Psychiatry Neurol. 28, 99-107.

[66] Ducharme S, Bajestan S, Dickerson BC, Voon V (2017) Psychiatric Presentations of C9orf72 Mutation: What Are the Diagnostic Implications for Clinicians? J. Neuropsychiatry Clin.

Neurosci. 29, 195-205. 
[67] Zanardini R, Ciani M, Benussi L, Ghidoni R (2016) Molecular Pathways Bridging Frontotemporal Lobar Degeneration and Psychiatric Disorders. Front. Aging Neurosci. 8, 10.

[68] Mendez M (2018) Manic behavior and asymmetric right frontotemporal dementia from a novel progranulin mutation. Neuropsychiatr. Dis. Treat. Volume 14, 657-662.

[69] Rubino E, Vacca A, Gallone S, Govone F, Zucca M, Gai A, Ferrero P, Fenoglio P, Giordana MT, Rainero I (2017) Late onset bipolar disorder and frontotemporal dementia with mutation in progranulin gene: a case report. Amyotroph. Lateral Scler. Front. Degener. 18, 624-626.

[70] Gatto EM, Allegri RF, Da Prat G, Chrem Mendez P, Hanna DS, Dorschner MO, Surace EI, Zabetian CP, Mata IF (2017) Intrafamilial variable phenotype including corticobasal syndrome in a family with p.P301L mutation in the MAPT gene: first report in South America. Neurobiol. Aging 53, 195.e11-195.e17.

[71] Cheran G, Wu L, Lee S, Manoochehri M, Cines S, Fallon E, Lynch T, Heidebrink J, Paulson H, Goldman J, Huey E, Cosentino S (2019) Cognitive Indicators of Preclinical Behavioral Variant Frontotemporal Dementia in MAPT Carriers. J. Int. Neuropsychol. Soc. 25, 184-194.

[72] Gotovac K, Nikolac Perković M, Pivac N, Borovečki F (2016) Biomarkers of aggression in dementia. Prog. Neuro-Psychopharmacology Biol. Psychiatry 69, 125-130.

[73] Block NR, Sha SJ, Karydas AM, Fong JC, De May MG, Miller BL, Rosen HJ (2016) Frontotemporal Dementia and Psychiatric Illness: Emerging Clinical and Biological Links in Gene Carriers. Am. J. Geriatr. Psychiatry 24, 107-116.

[74] Logroscino G, Imbimbo BP, Lozupone M, Sardone R, Capozzo R, Battista P, Zecca C, Dibello V, Giannelli G, Bellomo A, Greco A, Daniele A, Seripa D, Panza F (2019) Promising therapies for the treatment of frontotemporal dementia clinical phenotypes: from symptomatic to disease-modifying drugs. Expert Opin. Pharmacother. 20, 1091-1107.

[75] Bei Hu, Ross L, Neuhaus J, Knopman D, Kramer J, Boeve B, Caselli RJ, Graff-Radford N, 
Mendez MF, Miller BL, Boxer AL (2010) Off-Label Medication Use in Frontotemporal Dementia. Am. J. Alzheimer's Dis. Other Dementiasr 25, 128-133.

[76] Tsai RM, Boxer AL (2016) Therapy and clinical trials in frontotemporal dementia: past, present, and future. J. Neurochem. 138, 211-221.

[77] Shinagawa S (2015) Neuropsychiatric Management of Young-Onset Dementias. Psychiatr. Clin. North Am. 38, 323-331.

[78] Buoli M, Serati M, Caldiroli A, Galimberti D, Scarpini E, Altamura AC (2017) Pharmacological Management of Psychiatric Symptoms in Frontotemporal Dementia: A Systematic Review. J. Geriatr. Psychiatry Neurol. 30, 162-169.

[79] Lin C-P, Chu C-P, Liu H-C (2016) Bupropion improved apathy in behavioral variant frontotemporal dementia: a case report. Neurocase 22, 466-468.

[80] Callegari I, Mattei C, Benassi F, Krueger F, Grafman J, Yaldizli Ö, Sassos D, Massucco D, Scialò C, Nobili F, Serrati C, Amore M, Cocito L, Emberti Gialloreti L, Pardini M (2016) Agomelatine Improves Apathy in Frontotemporal Dementia. Neurodegener. Dis. 16, 352356.

[81] Jha MK, Lambert ES, Beadles BA, Spradling B, Martinez R, Renfro N, Byerly M (2015) A Case of Frontotemporal Dementia Presenting With Treatment-Refractory Psychosis and Extreme Violence. J. Clin. Psychopharmacol. 35, 732-733.

[82] Kerrsens CJ, Pijnenburg YAL, Pijnenburg YAL (2008) Vulnerability to neuroleptic side effects in frontotemporal dementia. Eur. J. Neurol. 15, 111-112.

[83] Agarwal S, Ahmed RM, D’Mello M, Foxe D, Kaizik C, Kiernan MC, Halliday GM, Piguet O, Hodges JR (2019) Predictors of survival and progression in behavioural variant frontotemporal dementia. Eur. J. Neurol. 26, 774-779.

[84] Lee JS, Jung N-Y, Jang YK, Kim HJ, Seo SW, Lee J, Kim YJ, Lee J-H, Kim BC, Park K-W, 
Yoon SJ, Jeong JH, Kim SY, Kim SH, Kim E-J, Park K-C, Knopman DS, Na DL (2017)

Prognosis of Patients with Behavioral Variant Frontotemporal Dementia Who have Focal Versus Diffuse Frontal Atrophy. J. Clin. Neurol. 13, 234.

[85] Zucca M, Rubino E, Vacca A, Govone F, Gai A, De Martino P, Boschi S, Gentile S, Giordana MT, Rainero I (2019) High Risk of Suicide in Behavioral Variant Frontotemporal Dementia. Am. J. Alzheimer's Dis. Other Dementias ${ }^{\circledR}$ 34, 265-271. 


\section{TABLES}

$\mathbf{T}$

\begin{tabular}{|c|c|c|c|c|}
\hline FTDC & & DSM 5 & & Differences \\
\hline Possible bvFTD & $\begin{array}{l}\text { Three or more of the } \\
\text { following } 6 \text { features: } \\
\text { Early behavioural } \\
\text { disinhibition } \\
\text { Early apathy or inertia } \\
\text { Early loss of sympathy } \\
\text { or empathy } \\
\text { Early perseverative, } \\
\text { stereotyped or compulsive/ } \\
\text { ritualistic } \\
\text { behaviours } \\
\text { Hyperorality and } \\
\text { dietary changes } \\
\text { Deficits in executive } \\
\text { function with relative } \\
\text { sparing of episodic } \\
\text { memory and visuospatial } \\
\text { skills (as determined by } \\
\text { structured } \\
\text { neuropsychological } \\
\text { testing) }\end{array}$ & $\begin{array}{l}\text { Possible (mild or major) } \\
\text { bvFTNCD }\end{array}$ & $\begin{array}{l}\text { Prominent decline in } \\
\text { social cognition AND/OR } \\
\text { executive function with } \\
\text { relative sparing of memory } \\
\text { and perceptual-motor } \\
\text { (visuospatial) function, } \\
\text { AND three or more of the } \\
\text { following } 5 \text { features: } \\
\rightarrow \text { Behavioral } \\
\text { disinhibition } \\
\text { Apathy/inertia } \\
\text { Loss of sympathy/ } \\
\text { empathy } \\
- \text { Perseverative, } \\
\text { stereotyped or compulsive/ } \\
\text { ritualistic } \\
\text { behaviour } \\
- \text { Hyperorality and } \\
\text { dietary changes }\end{array}$ & $\begin{array}{l}\text { DSM-5 requires cognitive } \\
\text { impairment (in social } \\
\text { cognition and/or executive } \\
\text { function) to be present; } \\
\text { FTDC makes it optional } \\
\text { FTDC specifies 'early' as } \\
\text { occurring within } 3 \text { years of } \\
\text { presentation }\end{array}$ \\
\hline Probable bvFTD & $\begin{array}{l}\text { Possible bvFTD AND } \\
\text { evidence of BOTH the } \\
\text { following: } \\
\text { Significant functional } \\
\text { decline } \\
\text { Frontal and/or anterior } \\
\text { temporal lobe atrophy on } \\
\text { MRI or CT, or frontal and/ } \\
\text { or temporal hypoperfusion } \\
\text { or hypometabolism on } \\
\text { PET or SPECT }\end{array}$ & $\begin{array}{l}\text { Probable (mild or major) } \\
\text { bvFTNCD }\end{array}$ & $\begin{array}{l}\text { Possible bvFTD AND } \\
\text { evidence of EITHER of } \\
\text { the following: } \\
\text { An FTLD pathogenic } \\
\text { Mutation } \\
\text { Disproportionate } \\
\text { frontal or temporal lobe } \\
\text { involvement on } \\
\text { neuroimaging }\end{array}$ & $\begin{array}{l}\text { DSM-5 requires functional } \\
\text { decline at } \\
\text { the level of syndromic } \\
\text { diagnosis of Major } \\
\text { NCD, before bvFTD } \\
\text { subtype; FTDC does } \\
\text { not distinguish bvFTD in } \\
\text { mild/major categories } \\
\text { DSM-5 places genetic } \\
\text { mutations as evidence of } \\
\text { probable bvFTD; FTDC } \\
\text { places genetic mutations } \\
\text { as evidence of definitive } \\
\text { bvFTD (see below) }\end{array}$ \\
\hline Definite bvFTD & $\begin{array}{l}\text { Possible OR probable } \\
\text { bvFTD AND evidence of } \\
\text { EITHER of the following: } \\
>\text { Histopathological } \\
\text { changes consistent with } \\
\text { FTLD on biopsy or } \\
\text { autopsy } \\
>\text { Presence of known } \\
\text { FTLD pathogenic genetic } \\
\text { mutation }\end{array}$ & Not applicable & $\begin{array}{l}\text { Not applicable: clinical } \\
\text { diagnosis only }\end{array}$ & $\begin{array}{l}\text { DSM-5 does not provide a } \\
\text { definite (mild or major) } \\
\text { bvFTNCD diagnostic } \\
\text { category }\end{array}$ \\
\hline
\end{tabular}

Legend: FTLD, frontotemporal lobar degeneration; FTNCD, Frontotemporal Neurocognitive Disorder; PET, positron emission tomography; SPECT, single-photon emission CT.

Table 2: most recent investigations orienting differential diagnosis between bvFTD and primary psychiatric disorders. 


\begin{tabular}{|c|c|c|}
\hline Investigation & BvFTD & $\begin{array}{l}\text { Primary psychiatric } \\
\text { disorders }\end{array}$ \\
\hline $\begin{array}{l}\text { History and clinical } \\
\text { examination }\end{array}$ & $\begin{array}{l}\text { Later/insidious onset, positive } \\
\text { family history for dementia, } \\
\text { progressive course, presence } \\
\text { progressive cognitive } \\
\text { impairment, poor response to } \\
\text { psychiatric treatments } \\
\text { (Galimberti, 2015). }\end{array}$ & $\begin{array}{l}\text { Early acute/subacute onset, } \\
\text { positive family history of } \\
\text { mood disorders, history of } \\
\text { multiple mood episodes, } \\
\text { presence of comorbidity } \\
\text { (anxiety and substance use } \\
\text { disorders), suicidal ideation } \\
\text { and/or previous suicide } \\
\text { attempts, inter-episodic } \\
\text { complete or partial recovery } \\
\text { and cognitive impairment } \\
\text { mostly limited to affective } \\
\text { episodes (Galimberti, 2015). }\end{array}$ \\
\hline $\begin{array}{l}\text { Psychometric evaluation } \\
\text { (PANSS, MADRS, SRI) }\end{array}$ & $\begin{array}{l}\text { Stereotypical thinking and } \\
\text { difficulties in abstract thinking } \\
\text { (Dols, 2016). } \\
\text { Significantly higher PANSS } \\
\text { total score of the negative } \\
\text { subscale (Gossink, 2016). }\end{array}$ & $\begin{array}{l}\text { Low SRI and high MADRS } \\
\text { score (Dols, 2016b). } \\
\text { Higher rate of symptoms } \\
\text { belonging to the anxiety } \\
\text { spectrum measured by the } \\
\text { PANSS scale (Gossink, 2016). }\end{array}$ \\
\hline Neuropsychological tests & $\begin{array}{l}\text { Impairment in letter fluency } \\
\text { and immediate memory (Chan, } \\
2015 \text { ) and progressive } \\
\text { worsening of frontal } \\
\text { behavioural symptoms (Reus, } \\
\text { 2018). }\end{array}$ & $\begin{array}{l}\text { Impairment in confrontation } \\
\text { naming and non-verbal } \\
\text { reasoning (Chan, 2015). }\end{array}$ \\
\hline CSF biomarkers & $\begin{array}{l}\text { High levels of CSF NFL and } \\
\text { YKL40; reduced p-tau/tau ratio } \\
\text { (Vijverbergs, 2017). }\end{array}$ & \\
\hline Serum biomarkers & $\begin{array}{l}\text { Elevated NFL levels (Al } \\
\text { Shweiki, 2019). }\end{array}$ & \\
\hline Magnetic resonance imaging & $\begin{array}{l}\text { Volumetric reductions in the } \\
\text { dorsolateral prefrontal cortex } \\
\text { and within the orbitofrontal } \\
\text { cortex and temporo-parietal } \\
\text { regions (Baez, 2019). } \\
\text { Ex ten s i v e volum etric } \\
\text { abnormalities within the limbic } \\
\text { lobe (Delvecchio, 2019). }\end{array}$ & $\begin{array}{l}\text { Grey matter reduction in the } \\
\text { ventrolateral prefrontal cortex, } \\
\text { greater grey matter volumes in } \\
\text { t h e c a u d t e n u c l e u s } \\
\text { (Delvecchio, 2019). }\end{array}$ \\
\hline
\end{tabular}




\begin{tabular}{|l|l|l|}
\hline Voxel based morphometry & $\begin{array}{l}\text { Decrease in gray matter } \\
\text { volume in frontal, temporal } \\
\text { and parietal regions (Sellami, } \\
\text { 2018). }\end{array}$ & \\
\hline Positron-emission tomography & $\begin{array}{l}\text { Metabolic impairments within } \\
\text { the orbitofrontal and temporal } \\
\text { cortex, metabolic abnormalities } \\
\text { within the limbic lobe and } \\
\text { greater metabolism in caudate } \\
\text { nucleus (Delvecchio, 2019). }\end{array}$ & $\begin{array}{l}\text { Lower metabolism in the } \\
\text { caudate nucleus (Delvecchio, }\end{array}$ \\
\hline Genetic testing & $\begin{array}{l}\text { C92ORF, GRN mutation and } \\
\text { MAPT mutation (Galimberti, } \\
\text { 2015). }\end{array}$ \\
\hline Neuropathological examination & $\begin{array}{l}\text { TDP43 and Tau-positive } \\
\text { inclusions (Young, 2018). }\end{array}$ \\
\hline
\end{tabular}

Legend: PANSS: Positive and Negative Syndrome Scale, SRI: Stereotypy Rating Inventory, MADRS: Montgomery-Åsberg Depression Rating Scale, CSF: Cerebro-spinal fluid, NFL: neurofilament light polypeptide. 